\title{
The region-wide implementation of a relationship education program for first time parents delivered in the maternal and child health care setting: evaluating reach and effectiveness
}

AUTHORS

ANN TAKET BA(Hons), $\mathrm{MSc}^{1}$

BETH R CRISP BA(Hons), BSW, BTheol, PhD²
1 School of Health and Social Development, Deakin University, Melbourne, Victoria, Australia

2 School of Health and Social Development, Deakin University, Geelong, Victoria, Australia

\section{CORRESPONDING AUTHOR}

BETH R CRISP School of Health and Social Development, Deakin University, Waterfront Campus, Locked Bag 20001, Geelong, Victoria, 3220 Australia. Email: beth.crisp@deakin.edu.au

\section{ABSTRACT}

Aims: To present the results of a region-wide evaluation of Baby Makes 3, a brief relationship education program for first time parents implemented in the maternal and child health setting.

Background: The program is designed to utilise the 'teachable moment' provided by the birth of the first child, and strengthen the couple relationship, promoting gender equity and preventing intimate partner violence. The literature contains only a few similar examples, none of which have been implemented on a region-wide scale in a rural context.

Participants: First time parents in the Great South Coast Region of Victoria, irrespective of whether they had participated in Baby Makes 3, group facilitators, and other stakeholders involved in the program across the region including maternal and child health nurses.
Methods: Interviews were conducted with parents, group facilitators and other stakeholders. Routinely collected surveys completed by parents and group facilitators were also analysed. Data was collected throughout the period April 2013 to August 2015.

Findings: Fewer than one-third of new parents in the region participated in Baby Makes 3. Parents, group facilitators and other stakeholders all made suggestions as to how program reach could be improved. These included the need to take account of key components of rural life including farm work and not clashing with sporting activities. Nevertheless, for those who participated, the program was judged highly effective according to both parents and staff. Additionally, parents valued the social interaction generated by the program as an outcome in itself, connected to the value of the program in normalising the challenges they were facing as new parents. Minimal negative effects were identified. 
Discussion: Transition to parenthood is a time when many parents are open to exploring gender roles and expectations within their relationships, especially in a context in which the challenges of parenting are normalised. However, the implementation of such a program which has been designed in an urban context may require modifications when delivered in a rural area.

Conclusion: Parenting programs are just as necessary in rural as in urban contexts. Furthermore, modifying the program to commence prior to the birth of a child further work may improve program reach.
What is already known about this topic?

- The birth of the first child, has been found in urban settings, to be a time when parents are open to brief interventions which lead to improved awareness, communication skills, attitudes and behaviours supportive of gender equity and a strengthened couple relationship.

What this paper adds:

- Programs which promote gender equity and respectful relationships are beneficial to new parents in rural areas, but effective implementation requires taking into account the characteristics of local communities.

Keywords: Maternal and child health; nurses; midwives; gender equity, relationship education; prevention of intimate partner violence; rurality

\section{INTRODUCTION}

Gender roles and relations become more traditional in the year following the first child's birth. ${ }^{1}$ This can create power imbalances in relationships between men and women, including couples who previously professed little support for traditional gender roles. ${ }^{2}$ When life circumstances are such that people are particularly receptive to new knowledge, prompting reflection on attitudes held and consideration of behaviour change, a "teachable moment" emerges.3,4 One such teachable moment is the transition to parenthood.5,6 Programs like Baby Makes 3, are explicitly designed to target this time when parents-to-be often seek out information to prepare for and respond to the arrival of a new family member, and are likely to be motivated to make changes and/ or have the opportunity or capacity to do so. ${ }^{5}$

Hence, a brief, three session program that focuses on strengthening the couple relationship, by promoting gender equity, was developed. As such, Baby Makes 3 is one of very few relationship education programs specifically designed to prevent violence against women who are mothers..$^{7-10}$ These contrast with the growing proliferation of programs aimed at parents which focus on the parent-child relationship, child development, and seek to enhance parenting skills and confidence in parenting. ${ }^{11-13}$ If relationships are explored, this tends to be around the extent of conflict around parenting practices. ${ }^{14}$

That most programs for new parents place little emphasis on their relationship is unsurprising. Unlike Baby Makes $3,{ }^{15}$ most programs for parents are typically aimed at mothers, with the involvement of fathers not considered essential. ${ }^{14,16,17}$ Even if they are interested, program design and delivery often prevent fathers from participating. ${ }^{18}$
Some programs focus on "hard-to-reach" or high-risk groups rather than on all new parents. Baby Steps, ${ }^{7}$ developed and implemented in the UK, begins with referral or self-referral in early pregnancy. The American Young Parenthood Program is the most different to Baby Makes 3, being based on 8-12 weekly sessions delivered to couples in the antenatal period by a counsellor aimed at promoting positive relationship skills, following an assessment process that included interviewbased screening for the occurrence of intimate partner violence (administered to parents in separate meetings). ${ }^{8}$ This is an example of a program based on assessment followed by tailored education, as opposed to the broadly curriculum-based knowledge and skills training of other programs.

Baby Makes 3 was originally developed by Whitehorse Community Health Service (now Carrington Health) and the City of Whitehorse in metropolitan Melbourne to complement existing new parent programs run by maternal and child health services which are usually attended by mothers and focus on aspects of child health rather than the parental relationship. ${ }^{2}$ The program, which seeks to prevent violence by promoting respect and equality between couples, is premised on evidence that addressing gender inequality is critical in addressing, including preventing, genderbased violence. ${ }^{19}$ By being offered to all first-time parents by maternal and child health staff, it engages with couples at this critical time, many of whom found the program enabled them to adopt greater equality in their relationships. As such, the initial Baby Makes 3 program was found to be an effective and cost-efficient violence prevention strategy. ${ }^{2}$ 
The current study offered an opportunity to investigate the implementation of Baby Makes 3 in the five local government areas (LGAs) in south-western Victoria, which form the Great South Coast Region (Warrnambool City Council, Corangamite Shire, Glenelg Shire, Shire of Moyne, and South Grampians Shire). This region comprises 10\% of Victoria's landmass but less than $2 \%$ of the population. ${ }^{20}$ As such it is relatively sparsely populated with distances of up to 100 $\mathrm{km}$ between major centres within the region. Programs developed in urban contexts often face different challenges when implemented in rural and regional settings, ${ }^{21}$ prior to this study how Baby Makes 3 would work in a rural context was unknown.

Baby Makes 3 was delivered as an opt-out program, forming part of a series of sessions offered to new parents in each of the LGAs after the birth. The positioning of the three Baby Makes 3 sessions in the new parent groups varied over the course of the project and between LGAs. Baby Makes 3 sessions were offered in the early evening, usually at the maternal and child health centres, whereas the rest of the new parent group sessions were delivered in the daytime. The program consists of three sessions, facilitated by a mixed gender pair of facilitators.

Information about Baby Makes 3 was usually distributed as part of the information offered on new parent groups by maternal and child health nurses following the birth of the child. One variant which was trialled in Glenelg Shire involved a single session in antenatal classes, as a way of introducing future parents to the post-birth groups. Information about Baby Makes 3 was offered verbally and/ or in written form (practices varied according to LGA) and reinforced during further contact with maternal and child health services; the project manager or Baby Makes 3 group facilitators would often attend one of the new parent group sessions to introduce the program and answer questions. Single parents were not excluded from Baby Makes 3. This was a deliberate decision, made in view of the lack of other groups available, and to allow them to focus on past and/or future relationships.

\section{THE STUDY}

\section{AIM}

The aim of the study was to evaluate the region-wide implementation of the Baby Makes 3 program in a nonmetropolitan setting over the years 2013 to 2015.

\section{DESIGN}

The overarching framework used was that of theory-based evaluation drawing on elements of realist and theory of change evaluation. ${ }^{22-24}$ The longitudinal, mixed-methods study employed a fully mixed concurrent equal status design ${ }^{25}$ where the timing of the different components of the evaluation was deliberately selected to minimise potential sources of bias and avoid compromising response rates to surveys. The design enabled the exploration of outcomes during the three years, and also gathered data to explore and understand how and why the particular patterns of outcomes came about, including factors in the wider context that were important either positively or negatively. The evaluation used data from: interviews with parents, group facilitators, and other key stakeholders in the program including maternal and child health nurses; surveys completed by parents and facilitators; and routinely collected data. It examined the impact of Baby Makes 3 on new parents and the uptake of the program across the region, and explored the program delivery factors that underlay these outcomes.

\section{PARTICIPANTS}

All first-time parents in the Great South Coast Region, irrespective of whether they had participated in Baby Makes 3 were invited to participate in interviews about the program. Invitations to participate were distributed by program staff, and names and contact details only provided to the researchers by individuals who wanted to be interviewed. Similarly, the regional coordinator distributed invitations to be interviewed to all group facilitators and other key stakeholders.

Surveys of all parents were conducted at the end of the third session and of all facilitators of Baby Makes 3 groups after each group session.

\section{DATA COLLECTION}

A summary of the six data sets used in the analysis reported in this paper is shown in Table 1. Details of the data collected in each set, and when the data was collected, are described below.

\section{INTERVIEWS}

All interviews were carried out by telephone, digitally recorded and then transcribed by a specialist firm. Immediately following the interview, the interviewer recorded post interview notes on anything that struck them particularly about the interview and on positive features of the program and any difficulties/challenges. Transcripts were checked and anonymised by the interviewer, prior to analysis.

For the interviews with parents, a mixed gender team of interviewers was used, with gender matched to interviewee wherever possible. Interviews with parents were carried out using a topic guide with sections on: receiving the invitation to participate and making the decision whether to attend or not, for those parents who did not attend at all or attended only some of the sessions the reasons were explored and what, if anything would have made their decision different; expectations on new mothers; changes if any in who does what at home; how has your relationship with your partner 


\section{TABLE 1: THE DIFFERENT DATA SETS USED IN THE EVALUATION}

\begin{tabular}{|c|c|c|}
\hline Data set & Features, including sample size and response rate & $\begin{array}{l}\text { Time period over } \\
\text { which data collected }\end{array}$ \\
\hline 1. Interviews with parents & $\begin{array}{l}\text { Invitations sent to all new parents, via the mother; } 40 \text { interviews in total. Response } \\
\text { rates of approximately: } 6.4 \% \text { women, } 3.6 \% \text { men. Included varied levels of attendance } \\
\text { at the program, and time since program received, from one month up to } 15 \text { months. }\end{array}$ & February to June 2015 \\
\hline $\begin{array}{l}\text { 2. Interviews with parents } \\
\text { who attended antenatal } \\
\text { session }\end{array}$ & $\begin{array}{l}\text { Recruited from those attending antenatal session; four interviews in total, , response } \\
\text { rate approximately } 10 \% .\end{array}$ & $\begin{array}{l}\text { August to October } \\
2015\end{array}$ \\
\hline $\begin{array}{l}\text { 3. Interviews with Baby } \\
\text { Makes } 3 \text { facilitators }\end{array}$ & $\begin{array}{l}\text { Invitations sent to all trained facilitators who had facilitated at least one complete } \\
\text { program; } 10 \text { interviews in total, representing a response rate of } 56 \% \text {. }\end{array}$ & July and August 2015 \\
\hline $\begin{array}{l}\text { 4. Interviews with maternal } \\
\text { and child health staff and } \\
\text { other stakeholders }\end{array}$ & 10 interviews in total, response rate approximately $30 \%$. & $\begin{array}{l}\text { February-March } 2014 \\
\text { and September } 2015\end{array}$ \\
\hline 5. Parent survey & Filled in at end of third session of program; $n=342$ (response rate high, over $90 \%$ ) & $\begin{array}{l}\text { May } 2013 \text { and October } \\
2015\end{array}$ \\
\hline
\end{tabular}

changed, if at all, since the birth; changes in your and your partners lives since the birth; for those who attended at least some of the program: the changes, if any, the program made for your situation, most important thing about the program for you, for your partner. For those parents who attended an antenatal session as well, an additional section was added to the topic guide at the beginning which explored views of the antenatal session. Interviews with parents lasted between five and 45 minutes with an average length of 21 minutes for mothers and 13 minutes for fathers.

Interviews with group facilitators were carried out using a topic guide with sections on: the extent of their involvement as a facilitator; perspectives on the aims and objectives of the program; what has worked well in terms of component design and implementation and any views on the key factors responsible; any difficulties that have been encountered in terms of design or implementation and how these might be addressed; whether the program is reaching the target group in a uniform fashion; future development. The interviews with group facilitators ranged in length from 30 to 60 minutes.

Interviews of a similar length were carried out with other program stakeholders using a topic guide with similar sections to those for the facilitators except that the nature of their involvement with the program was also explored. In discussing their views on the remaining sections they were encouraged to reflect on what they had heard from facilitators and parents who had attended the program.

\section{Parent survey}

The data collected was limited to 10 questions. Seven were closed questions: session date; location; mother or father; level of agreement with three statements about the enjoyability, relevance and helpfulness of the program, each measured on a 5 point Likert scale; overall rating of program, choice from 5 point scale (excellent to poor). There were three open questions: three main things I have learned from this program; how would you describe this program to another person who was thinking of doing it; any additional comments. Surveys were completed at the end of the third session, collected by the facilitators and forwarded to the regional coordinator.

\section{Facilitator survey}

Each pair of group facilitators completed the facilitator survey at the end of every program session. The data collected included six open questions on: practical issues that need to be addressed; session highlights/strengths; areas for improvement; challenges and how they were addressed; concerns; general comments. Numbers of mothers and fathers attending were also recorded and sent to the regional coordinator.

\section{ETHICAL CONSIDERATIONS}

Ethics clearance was granted by Deakin University on 15 May 2014 for the interviews with parents (project reference HEAG-H-58_2014) with an amendment dated 31 March 2015 to cover interviews with parents who attended the antenatal session offered in Glenelg Shire; and on 14 April 2015 for the staff interviews and other data analysis comprising the summative evaluation (project reference HEAG-H 36_2015).

\section{DATA ANALYSIS}

A mix of descriptive and inferential statistics was used to analyse quantitative data. Excel 2013 was used to support quantitative data analysis. ${ }^{26} \mathrm{~A}$ conservative significance level of 0.01 is used for reporting results as statistically significant. 
A combination of deductive and inductive thematic analysis was used to analyse qualitative data from interviews and open questions on surveys and questionnaires. ${ }^{27,28}$ Nvivo, version 10 was used to support qualitative analyses. ${ }^{29}$

\section{VALIDITY AND RIGOUR}

The evaluation used a wide range of different sources of data, allowing for triangulation between different sources in order to test validity through convergence from different data sources. For each of the different data sets, a single member of the research team carried out the qualitative analysis, which was then checked and agreed by other team members to ensure validity and rigour.

\section{RESULTS/FINDINGS}

Basic characteristics of the samples are summarised in Table 2. A deliberate decision was made not to collect socio-demographic data (beyond gender), given concerns about the burden of data collection, the possible perceived intrusiveness of questions and likely interference with building rapport in an interview situation, thereby risking comprising the richness of data obtained from the interviews.
TABLE 2: CHARACTERISTICS OF SAMPLES

\begin{tabular}{|c|c|c|c|}
\hline Data set & $\begin{array}{r}\text { Total } \\
\text { sample } \\
\text { size }\end{array}$ & $\begin{array}{l}\text { Number } \\
\text { of males }\end{array}$ & $\begin{array}{r}\text { Number } \\
\text { of } \\
\text { females }\end{array}$ \\
\hline 1. Interviews with parents & 40 & 14 & 26 \\
\hline $\begin{array}{l}\text { 2. Interviews with parents who } \\
\text { attended antenatal session }\end{array}$ & 4 & 1 & 3 \\
\hline $\begin{array}{l}\text { 3. Interviews with Baby Makes } 3 \\
\text { facilitators }\end{array}$ & 10 & 6 & 4 \\
\hline $\begin{array}{l}\text { 4. Interviews with maternal and } \\
\text { child health staff and other } \\
\text { stakeholders }\end{array}$ & 10 & 1 & 9 \\
\hline $\begin{array}{l}\text { 5. Parents' views immediately } \\
\text { post-program }\end{array}$ & $342^{\#}$ & 156 & 185 \\
\hline 6. Facilitator session evaluation & $87^{\star}$ & * & * \\
\hline
\end{tabular}

TABLE 3: THE REACH OF BABY MAKES 3 IN THE GREAT SOUTH COAST REGION

\begin{tabular}{|c|c|c|c|c|}
\hline Overall reach & $\begin{array}{r}\text { No. parents } \\
\text { completing third } \\
\text { session }\end{array}$ & Completion rate & $\begin{array}{l}\text { No. parents } \\
\text { participating in at } \\
\text { least one session }{ }^{1}\end{array}$ & $\begin{array}{r}\text { Involvement } \\
\text { (partial completion) } \\
\text { rate }\end{array}$ \\
\hline 1 April 2013 to 31 March 2014 & 162 & $18 \%$ & 234 & $26 \%$ \\
\hline 1 April 2014 to 31 March 2015 & 111 & $12 \%$ & 186 & $21 \%$ \\
\hline \multicolumn{5}{|l|}{ By local government area } \\
\hline \multicolumn{5}{|l|}{ Warrnambool and Moyne ${ }^{2}$} \\
\hline 2013-14 & 81 & $17 \%$ & 108 & $23 \%$ \\
\hline 2014-15 & 67 & $13 \%$ & 89 & $18 \%$ \\
\hline \multicolumn{5}{|l|}{ Glenelg } \\
\hline 2013-14 & 24 & $13 \%$ & 49 & $27 \%$ \\
\hline 2014-15 & 14 & $10 \%$ & 34 & $24 \%$ \\
\hline 2013-14 & 31 & $21 \%$ & 51 & $35 \%$ \\
\hline 2014-15 & 19 & $14 \%$ & 38 & $29 \%$ \\
\hline \multicolumn{5}{|l|}{ Corangamite } \\
\hline 2013-14 & 26 & $29 \%$ & 26 & $29 \%$ \\
\hline 2014-15 & 11 & $9 \%$ & 24 & $21 \%$ \\
\hline
\end{tabular}

Notes

1. Calculated from the maximum numbers attending in a program. Note that this will be an underestimate since sometimes parents missed session 1 and/or 2 but attended later sessions

2. From January 2014, parents in Moyne were invited to attend the program in Warrnambool, so results are presented for the two LGAs combined. 


\section{PROGRAM REACH}

The reach, or uptake, of the program was calculated for two successive 12-month periods, see Table 3. The table contains two slightly different measures of reach, completion and involvement (or partial completion) by comparing participants with birth registration data for first time parents in each LGA. The first of these is based on the number of parents who completed the third session of the program; the second is based on an estimate of the number of parents who completed at least one session of Baby Makes 3. This second measure of reach is an underestimate, but it is not possible to improve on it, since full registers of attendance at each session were not maintained.

The overall completion rate for the program in 2014-15 was $12 \%$ of new parents, with variation by LGA from $9 \%$ to $14 \%$. The overall involvement rate for the program was $21 \%$ of new parents, with variation by LGA from 18 to $29 \%$. The decreases in completion and involvement rates from 2013-14 to 2014-15 are most likely caused by a combination of the reduced accessibility of program sessions (with parents in Moyne having to travel further to attend) and the inability to run any programs in Corangamite in 2015 owing to low birth numbers.

Accurate calculation of the representativeness of those who participated in Baby Makes 3 is not possible given the data available. Such information is obtainable only from the interviews carried out with parents who participated in the program, with program facilitators and with maternal and child health staff. All of these sources suggested underrepresentation in the same specific groups: Indigenous parents; young parents; and parents with lower socioeconomic status. However, none of these groups was completely absent from the program.

\section{Understanding and improving reach}

Data analysis suggests a number of factors that are responsible for the level of reach obtained. Interviews with parents, facilitators and stakeholders all recognised the barriers posed by the distance and time required to travel to Baby Makes 3 sessions, as did feedback given on the parent surveys.

The program was deliberately run in the early evening to facilitate the attendance of fathers, and while there is no doubt that the timeslot was more convenient than one during the day (the timing of new parent groups), travel in the evening around the time that parents are trying to establish as bath and bed time was not ideal for many and was particularly unpopular in winter months. There were also significant difficulties for those involved in shift work, farm work, fly-in fly-out working or sporting activities. Offering the program at weekends was suggested by a number of parents and facilitators, although most considered that no single solution would suit everyone. Delivering the whole program in a single day was also suggested but this would remove the opportunity for "homework" between sessions, something that parents reported benefitting from. Others suggested delivering it in two weekend sessions, separated by two or three weeks.

Another barrier to involvement was lack of information about the program and what it would involve. For those who had chosen not to attend new parent groups (39\% of new mothers in 2013-14 and 35\% in 2014-15 across the region), the only source of information about the program was the written or verbal information from maternal and child health about new parent groups and the integrated Baby Makes 3 sessions. The interviews with parents eligible for Baby Makes 3 who did not attend demonstrated that this did not always succeed in communicating the availability of the program.

\section{PROGRAM EFFECTIVENESS}

This section examines the impact on important outcomes, including potential negative effects. Different sources of data have provided a wealth of evidence that parents who attended the program received a variety of benefits from it. Throughout this section, data from interviews with parents and facilitators is used as well as data from the parent and facilitator surveys. The interviews with parents are a particularly important source of data here because the vast majority of parents who had attended were interviewed at least three months after the end of the program and in some cases up to 15 months after. This meant they had had a good amount of time for any learning and skills development to have an impact on them and their relationship. The changes they reported were highly consistent with those reported in the parent survey completed by parents at the end of the third session, indicating that the short-term impacts reported immediately following program completion were maintained in at least the short to medium term. Table 4 summarises the key findings against the indicators set out in the Baby Makes 3 theory of change model. ${ }^{2}$

Baby Makes 3 received positive feedback from the overwhelming majority of parents interviewed who had attended at least some of the program as well as from the overwhelming majority of the parents completing the survey at the end of the final Baby Makes 3 session: $98 \%$ overall rated the program as good, very good or excellent; 94\% agreeing or strongly agreeing that the program was helpful and $96 \%$ agreeing or strongly agreeing that the program was enjoyable. The following quotes are typical of their overall view of the program:

I was really impressed with it, probably because I hadn't really been in a group situation like that before. I definitely enjoyed the parts where the men were separated from the women and then they were brought back into the room to discuss the same answers, and that was really insightful.... I've kept in touch with a couple of blokes from the course .... [People] shared 
TABLE 4: SUMMARY OF EVIDENCE AGAINST INDICATORS FOR THE BABY MAKES 3 THEORY OF CHANGE MODEL

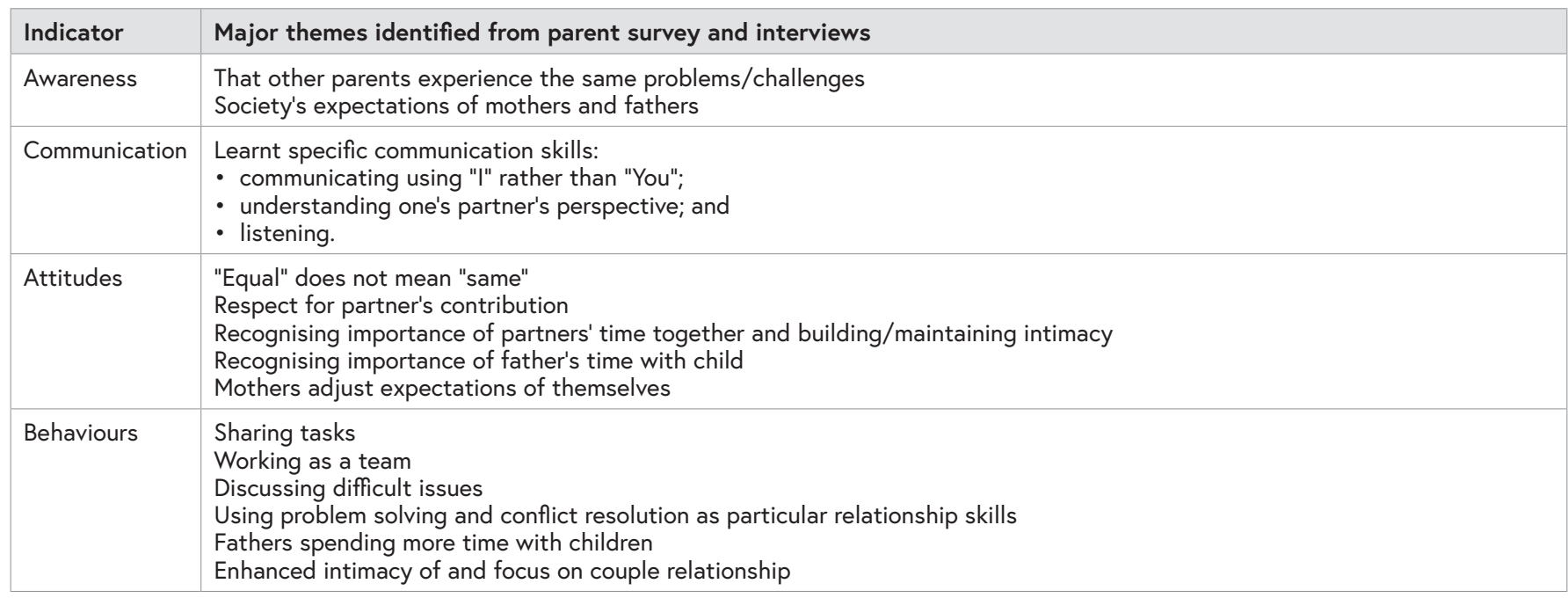

some brilliant stories and some great experiences and that time to actually tell their story I think was really cathartic for a lot of people, and added to that growing sense of confidence, that things are going to be all right and that we're doing the right thing. (Father, interview)

Fantastic. Opened my eyes to focusing more on our husbandwife relationship. (Mother, parent survey)

An impact reported as important by parents in interviews, and reflected explicitly in one of the quotes above, was the social connections parents made, and maintained, as a result of participating in Baby Makes 3. This was also reported on the parent surveys completed at the end of the third session, and was commented on by several facilitators when they reflected on the value of the program. Improved social connectedness is important for protection and promotion of health, and is particularly key for those living in rural and regional contexts. This impact was not identified in the original theory of change underlying the program. ${ }^{2}$

Important changes included awareness of societal expectations of mothers and the extent of caring and domestic responsibilities assumed by mothers. Mothers reported that they had gained an awareness of the high expectations they placed on themselves, which were not necessarily reflective of expectations placed on them by others. Many mothers realised that they needed to judge themselves less harshly, that they would not necessarily be able to achieve as much as they had previously expected to. Prior to attending Baby Makes 3, many of the fathers had not realised the societal expectations placed on new mothers. As a result of this realisation, some fathers reported that they were better able to support their partner.

Other important impacts reported in interviews with parents were experienced within the couple relationship, with parents reporting enhanced communication and conflict resolution skills, and an increased focus on the couple relationship. This strongly reinforces the data from the parent surveys and offers reassurances that the learning about communication and conflict resolution skills reported immediately after the final sessions (which focused on these skills) is not merely an effect of short-term recall or social desirability bias. Interviews with facilitators also reinforced the value of the program in terms of stimulating increased discussion within couples on topics not previously discussed.

These in turn produced changes in behaviour, such as mothers adjusting their expectations of themselves, and fathers prioritising family over work and contributing more towards household tasks and childcare. All of these positive changes can be seen as supporting increased gender equity. The most common change in behaviour reported was that the father helped more with household and caring tasks, although the mother still did most:

Well I think there was the graph shown of how much dad time and how much mum time and how much together time with the baby, and I think that's been quite - [partner's name]'s been quite aware of that, so he's sort of - after the sessions he sort of made more time to have one-on-one time, like he gets up in the morning with the baby and I stay in bed and he has that one-on-one time before he goes to work, so that sort of started after that, and I think it's his little mission to not fall into that percentile. (Mother, interview)

Fathers talked about how recognising the expectations put on mothers enabled them to better support their partner, and to function as more of a team, as one of the fathers expressed it:

Yeah, the other thing I think that really helped us just understanding regardless of how much we share the roles and the duties, the expectation on [partner's name] ... so I think I was just able to support her a little bit more by understanding that, if that makes sense. (Father, interview) 


\section{POSSIBLE NEGATIVE EFFECTS}

One possible negative effect lay in the program being regarded as directed against men or negative about men. This was an issue that was raised unprompted by some parents in interviews, in the facilitators' survey, and in the parent survey. In the interviews with facilitators and stakeholders this issue was specifically explored if the participant had not raised it in response to open questions.

This issue was raised unprompted by four of the 10 facilitators interviewed, and all but one of the facilitators interviewed had noticed some of their group participants perceive elements of negativity towards men. In at least one case this resulted in the couple choosing not to attend the third session of the program, with the female partner reporting:

I know a lot of the males felt it was very critical towards the fathers. Yeah, so that's why we didn't go back for the last session, my partner just didn't - he didn't want to deal with it anymore... like they didn't refer to anything positive regarding the fathers. (Mother, interview)

No other negative effects were reported in interviews with parents when discussing the program's impact on them. Two aspects of program delivery were viewed negatively by parents: difficulty in feeling able to be honest, and the challenge of small groups. In the analysis of the parent surveys a small number of single mothers said the program was less relevant to them, although some reported it was useful. One single mother reported that she had sometimes felt awkward; this could be regarded as a negative effect. This was echoed by a number of facilitators, who said they sensed discomfort and awkwardness from some single mothers in their sessions.

\section{FINDINGS FROM THE ANTENATAL PILOT PROGRAM IN GLENELG SHIRE}

Analysis of uptake rates for Baby Makes 3 over its first year led to the suggestion of a brief introductory session in the antenatal setting, so that fathers-to-be could be introduced directly to the idea of the program. A pilot of this arrangement was carried out in Glenelg Shire from January 2015. All of the parents interviewed appreciated the value of the antenatal session as a taster for what was on offer in the postnatal program.

The reaction of the fathers to the session was extremely positive; all of them went on to attend the postnatal program with their partners and all reported that the decision to attend the postnatal session was made mutually with their partners and influenced by the antenatal session. Antenatal sessions were also suggested as a valuable addition in interviews with parents who had not experienced them, facilitators and maternal and child health staff. The facilitators and maternal child health staff linked these suggestions explicitly to improving uptake.

\section{DISCUSSION}

The results presented in this article for Baby Makes 3 are broadly consistent with those from the Hong Kong and UK which evidence a critical role for maternal and child health nurses in the promotion of gender equity and prevention of IPV.7,9,10 What is also similar is the positive feedback from parents about group discussions and active learning activities as opposed to more didactic presentations. As has also been found in an evaluation of Baby Makes 3 in an urban context which was conducted at a similar time to the current study, ${ }^{15,30}$ the findings presented here identify the importance of social interaction generated by the program as an outcome valued by parents. Also valued was the opportunity to normalise the challenges they were facing as new parents. The findings presented here for Baby Makes 3 are also highly consistent with earlier work which identified that: transition to parenthood is an under-utilised opportunity to deliver relationship education. ${ }^{31}$

Since the data presented here was collected, Baby Makes 3 has been implemented in a number of rural communities throughout Victoria. To the best of our knowledge no evaluations of these initiatives have been published, although there is a growing recognition that implementation requires taking into consideration specific factors of the target community. ${ }^{2}$ One of distinctive features of this evaluation is that it provides valuable insights into reaching potential participants in non-urban contexts. These include the need for a strategy of program delivery when there are too few births in an area to run a program in a year. The emergence of online parenting programs which have been developed in response to COVID-19 potentially provides another model for reaching new parents in rural areas who find it difficult to participate in the existing program format. $33-34$

Another key differentiating factor of this evaluation is its exploration of potential negative effects. While evaluations of parenting programs may reveal aims not fully realised, negative effects tend not to be mentioned. ${ }^{12,16,17}$

In terms of findings to date, of the other programs discussed earlier, only the Young Parenthood Program has been subject to an evaluation that included a comparison group. A cluster randomised trial of Becoming Parents has been registered but findings have not yet been reported. All of the studies reported thus far are relatively small in size, none of them report data on cost, and unlike the current study, none report on any resistance to the program or possible negative effects. Although the Young Parenthood Program is the least similar to Baby Makes 3, it is of interest, since the pilot randomised control trial ${ }^{8}$ included assessment of intimate partner violence (IPV) at baseline, three months after birth and 18 months after birth. The findings demonstrated that couples who were randomly assigned to the Young Parenthood Program were significantly less likely to have engaged in IPV at the first 
follow-up, compared to couples in the "treatment as usual" control group, but the strength of this finding diminished over time.

\section{STRENGTHS AND LIMITATIONS}

The evaluation reported here has both limitations and strengths. First and foremost of the limitations, the assessment of the impact of Baby Makes 3 relies mainly on self-reporting by parents. Secondly, only a very small number of parents in the interview sample had chosen not to attend the program, so it was not possible to explore any differences in attitudes and behaviour between those who had, and had not, attended the program. The evaluation does not therefore include a comparison group that did not attend the program.

A further limitation is the extremely restricted range of sociodemographic information collected on those who attended the program. A deliberate decision was made to restrict such data collection directly from parents, given concerns about the burden of data collection, the perceived intrusiveness of questions and likely interference with building rapport in an interview situation, thereby risking comprising the richness of data obtained from the interviews.

In the years since the data presented here was collected, Baby Makes 3 has transitioned from being a pilot program in a few locations to becoming established in a much wider range of Australian communities. Although the program specifications remain unchanged and hence these findings are still likely to remain relevant, applicability may be compromised if individual program providers are making adjustments to how they deliver Baby Makes 3 .

A particular strength of the evaluation has been the use of a wide range of different sources of data, allowing for triangulation between different sources. The interview sample sizes obtained, while not large, are sufficient for the type of qualitative analysis undertaken here. 35 The interviews of parents, group facilitators and other stakeholders yielded extremely rich data, which was invaluable in understanding the particular features of the program that were helpful to parents, the challenges in program delivery, and how these might be met in the future.

Three further strengths are connected with the interviews with parents. Firstly, all parents eligible for Baby Makes 3 were invited for interview and the invitation made clear that interviews were sought with those who had not attended the program at all or who had attended only part. Secondly parents were interviewed on their own, and usually by an interviewer of the same gender, both of which reduce the risk of social desirability bias. ${ }^{36}$ Thirdly, information provided in interviews suggested that the interview sample obtained was very diverse and were not drawn solely from a particular socio-demographic subset.

\section{CONCLUSION}

The study has demonstrated the feasibility of delivering, in a non-metropolitan regional setting, a program that succeeds in building the capacity of first-time parents to build equal and respectful relationships in response to the lifestyle and relationship changes that follow the birth of their first child, and reduce the risk of family violence. While involvement levels were not as high as desired, they represent a considerable achievement in the face of factors that were not under the program's control. Integration within the delivery of new parent groups was perceived positively, and delivery outside the 9 to 5 working day was also important, although did not enable everyone to attend.

The program successfully generated positive impacts, according to the overwhelming majority of the parents who attended all or part of the program and contributed their views to one or more parts of the evaluation. Minimal possible negative effects were identified, and the experience gained in program delivery should enable these to be further reduced in the future. As such these conclusions are very consistent with those reached in the original (metropolitan) evaluation of Baby Makes $3,{ }^{2}$ and demonstrate the program's applicability in a rural and regional setting. Findings from the antenatal session, together with the conclusions from the other programs which spanned both the perinatal period, indicate advantages of commencing such programs before the birth.

Acknowledgements: The authors would like to thank the team of researchers who worked with us on this study: Dr Cara Büsst, Dr Georgia Birch, Laura Coady, Dr Mark Furlong and Dr Sugi Selvarajah.

With many thanks to the lead agency, Warrnambool City Council, and the other partner organisations in the Great South Coast region for their role in collecting and supplying data to be used in this evaluation. We particularly acknowledge the key role played by the project manager Steve Dawkins.

Many thanks to all the people in the region who contributed their time to be interviewed for this evaluation: the program facilitators, other stakeholders and staff in the region and most especially the first-time parents.

Funding: This evaluation was funded by a grant from Warrnambool City Council, using funds received from the Victorian Department of Justice and Regulation under the Reducing Violence against Women and their Children grants program, 2013 to 2015.

Conflict of interest: No conflict of interest has been declared by the authors. 


\section{REFERENCES}

1. Katz-Wise S, Priess H, Hyde J. Gender-role attitudes and behaviour across the transition to parenthood. Dev Psychol. 2010;46(1):18-28.

2. Flynn D. Baby Makes 3: project report. Whitehorse Community Health Service. 2011

3. Lewis CE. Teaching medical students about disease prevention and health promotion. Public Health Rep.1982;97:210-5.

4. Nutting PA. Health promotion in primary medical care: problems and potential. Prev Med. 1986;15(5):537-48.

5. Olander EK, Darwin Z, Atkinson L, Smith DM and Gardner B. Beyond the 'teachable moment': a conceptual analysis of women's perinatal behaviour change. Women Birth. 2016;29(3):67-71.

6. Phelan S. Pregnancy: a 'teachable moment' for weight control and obesity prevention. Am J Obstet Gynecol. 2010;202(2):135. e1-8.

7. Coster D, Brookes H, Sanger C. Evaluation of the Baby Steps programme: pre and post measures study. London: NSPCC; 2015.

8. Florsheim P, McArthur L, Hudak C, Heavin S, Burrow-Sanchez J. The Young Parenthood Program: preventing intimate partner violence between adolescent mothers and young fathers. J Couple Relatsh Ther. 2011;10(2):117-34.

9. Tiwari A, Wong YHJ, Yuen F. Positive Fathering: a programme to enhance the mental health and marital relationship of expectant couples: dissemination report. Hong Kong: University of Hong Kong; 2011.

10. Tiwari A, Leung WC, Chow KM, Yuk FYK, Fong YTD, Yuen KHF, et al. Becoming Parents: a hospital-community partnership to enhance transition to parenthood: dissemination report. Hong Kong: University of Hong Kong.

11. Morris H, O'Connor A, Cummins J, Valentine C, Dwyer A, Goodyear M, et al. A pilot efficacy study of Parents Building Solutions: a universal parenting program using co-design and strength-based approaches. Child Youth Serv Rev. 2019;105:104447.

12. Pontoppidan M, Klest SK, Patras J, Rayce, BR. Effects of universally offered parenting interventions for parents with infants: a systematic review. BMJ Open 2016;6:e011706.

13. Suárez A, Byrne S, Rodrigo MJ. Effectiveness of a universal web-based parenting program to promote positive parenting patterns and predictors on program satisfaction. J Child Fam Stud. 2018;27:3345-57

14. Piotrowska PJ, Tully LA, Collins DAJ, Sawrikar V, Hawes D, Komonis ER, et al. ParentWorks: evaluation of an online, fatherinclusive, universal parenting intervention to reduce child conduct problems. Child Psychiatry Hum Dev. 2020;51:503-13.

15. Pfitzner N, Humphreys $C$, Hegarty K. Bringing men in from the margins: father-inclusive practices for the delivery of parenting interventions. Child Fam Soc Work. 2020;25(S1):198-206.

16. Lindsay G, Totsika V. The effectiveness of universal parenting programmes: the CANparent trial. BMC Psychol. 2017;5:35.

17. Sampaio F, Sarkadi A, Salari R, Zethraeus N, Felman I. Costs and effects of a universal parenting program delivered to parents of preschoolers. Eur J Public Health. 2015;25(6):1035-42.

18. Pfitzner N, Humphreys $C$, Hegarty K. Engaging men: a multilevel model to support father engagement. Child Fam Soc Work. 2017;22(1):537-47.
19. Our Watch, Australia's National Research Organisation for Women's Safety, Victorian Health Promotion Foundation. Change the story: a shared framework for the primary prevention of violence against women and their children in Australia. Our Watch. 2015. Available from: https:// d2bb010tdzqaq7.cloudfront.net/wp-content/uploads/ sites/2/2019/05/21025429/Change-the-story-frameworkprevent-violence-women-children-AA-new.pdf

20. Australian Bureau of Statistics. Data by region. Australian Bureau of Statistics. Canberra. 2014. Available from: https://dbr.abs.gov.au/

21. Maidment J, Bay U. Social work in rural Australia: enabling practice. Sydney: Allen \& Unwin; 2012.

22. Chen HT, Rossi PH. Evaluating with sense: the theory-driven approach. Eval Rev. 1983;7(3):283-302.

23. Pawson R, Tilley N. Realistic evaluation. London: Sage; 1997.

24. Connell JP, Kubisch AC, Schorr LB, Weiss CH. New approaches to evaluating community initiatives, vol. 1, concepts, methods and contexts. Washington, DC: Aspen Institute; 1995.

25. Leech NL, Onwuegbuzie AJ. A typology of mixed methods research designs. Qual Quant. 2009;43(2):265-75.

26. Excel 2013. Microsoft Corporation; 2013.

27. Braun V, Clarke V. Using thematic analysis in psychology. Qual Res Psychol. 2006;3(2):77-101.

28. Thomas DR. A general inductive approach for analyzing qualitative data. Am J Eval. 2006:27(2):237-46.

29. NVIVO qualitative data analysis software. QSR International Pty Ltd. Version 10. 2012

30. Pfitzner N, Humphreys C, Hegarty K. Engaging men as fathers: how gender influences men's involvement in Australian family health services. J Fam Issues. 2018;39(16):3956-85.

31. Hunter C, Commerford J. Relationship education and counselling: recent research findings. CFCA Paper No. 33 Melbourne: Australian Institute of Family Studies, 2015.

32. Carrington Health. Promoting equality in parenting, supporting families to thrive: program overview. healthAbility. 2020. Available from: https://assets.healthability.org.au/images/ Baby-Makes-3-Program-Overview.pdf

33. Cluver L, Lachman JM, Sherr L, Wessels I, Krug E, Rakotomalala S, et al. Parenting in a time of COVID-19. Lancet. 2020;395(10231):e64

34. Thomas A, Treloar M, Wynter K. Engaging fathers through childbirth education programs: optimising mothers', fathers' and babies' health outcomes. Aust Nurs. 2021;27(3):55.

35. Guest G, Bunce A, Johnson L. How many interviews are enough? An experiment with data saturation and variability. Field Methods. 2006;18(1):59-82.

36. Kane EW, Macaulay LJ. Interviewer gender and gender attitudes. Public Opin. Q. 1993;57(1):1-28. 